\title{
AL-A'RAF
}

Jurnal Pemikiran Islam dan Filsafat

SURAKARTA http://ejournal.iainsurakarta.ac.id/index.php/al-araf

ISSN: 1693-9867 (p); 2527-5119 (e)

DOI: $10.22515 /$ ajpif.v14i2.893

\section{KUPATAN, TRADISI UNTUK MELESTARIKAN AJARAN BERSEDEKAH, MEMPERKUAT TALI SILATURAHMI, DAN MEMULIAKAN TAMU}

\author{
Wildan Rijal Amin \\ UIN Sunan Kalijaga, Yogyakarta
}

\begin{tabular}{|c|c|}
\hline & Abstrak \\
\hline $\begin{array}{l}\text { Keywords: } \\
\text { Living hadith, } \\
\text { Selametan, and } \\
\text { Kupatan }\end{array}$ & $\begin{array}{l}\text { Tradisi Kupatan merupakan sebuah perayaan selametan yang } \\
\text { dipraktikkan oleh masyarakat Jawa di daerah Durenan, Trenggalek, } \\
\text { Jawa Timur, dengan cara open house agar dikunjungi oleh warga lain. } \\
\text { Saat perayaan, masyarakat menyiapkan hidangan ketupat untuk } \\
\text { para tamu pada hari kedelapan Hari Raya Idul Fitri, setelah enam } \\
\text { hari menjalankan puasa sunah Syawal. Tradisi yang berawal dari } \\
\text { mbah Mesir ini diteruskan oleh cucunya, Kyai Abdul Fattah Mu'in, } \\
\text { dan secara turun-temurun sudah dipraktikkan oleh masyarakat di } \\
\text { desa Durenan selama hampir } 200 \text { tahun. Dari studi living hadith } \\
\text { ditemukan bahwa tradisi ini merupakan bentuk praktik masyarakat } \\
\text { setempat atas ajaran Nabi Muhammad saw. yang berkaitan dengan } \\
\text { sedekah, memperkuat tali silaturahmi, dan memuliakan tamu agar } \\
\text { hidup menjadi lebih berkah. Para leluhur dan Kyai berperan sebagai } \\
\text { konektor yang menghubungkan antara teks, realitas sosial, dan } \\
\text { kehidupan masyarakat setempat yang diwujudkan dalam bentuk } \\
\text { praktik selametan ini. }\end{array}$ \\
\hline
\end{tabular}

\begin{abstract}
Abstrak
The Kupatan tradition is a kind of celebrating selametan which is practiced by the Javanese people of Durenan village, Trenggalek, East Java by opening houses in order to be visited by the other villagers/ guests. During the celebration, the people of Durenan prepared ketupat as its beverages for their guests on the day eight of Idl Fitr, after finishing the syawal fasting. The tradition which is coming from Mbah Mesir and followed by his grandchild, Kyai Abdul Fattah Mu'in, then practiced by the people of Durenan village heredity for almost 200 years. Based on the living hadith study found out that this tradition is part of the people of Durenan in practicing the Prophet Muhammad's Pbh. Teachings, which deals with the alms, strengthening people
\end{abstract}


brotherhood, and glorifying the guests to make the life to be more blessed. The ancestors and Kyai have the role to contextualize text, social reality, and local people daily life, which then practiced into this selametan tradition.

\section{Pendahuluan}

Bagi umat Islam, Nabi Muhammad saw. adalah sosok yang dijadikan panutan dalam kehidupan sehari-hari. Pada masa hidupnya, Nabi Muhammad saw. senantiasa memberikan arahan kepada umatnya tentang kebenaran, ataupun norma-norma yang terkandung dalam Alqur'an. Sabda Nabi tidak lepas dari situasi dan kondisi yang melingkupi masyarakat pada waktu itu, sehingga sangat kecil kemungkinan jika Nabi bersabda tanpa adanya problem mendasar. Di sinilah letak adanya keterkaitan antara ajaran Islam dengan konteks sosio-historis dan kultural pada waktu itu. ${ }^{1}$

Dalam tatanan kehidupan, figur Nabi menjadi tokoh sentral yang diikuti oleh umat Islam sampai akhir zaman. Di sinilah muncul berbagai persoalan terkait dengan kebutuhan dan perkembangan masyarakat yang semakin kompleks, diiringi dengan adanya rasa keingininan yang kuat untuk mengaplikasikan ajaran Islam dalam kehidupan sehari-hari sesuai dengan yang diajarkan oleh Nabi dalam konteks ruang dan waktu yang berbeda. Upaya untuk mengaplikasikan hadith dalam konteks sosial, budaya, politik, ekonomi, dan hukum yang berbeda ini dapat dikatakan sebagai bentuk hadith yang hidup dalam masyarakat, atau biasa disebut dengan istilah living hadith. ${ }^{2}$

Living hadith merupakan sebuah tulisan, bacaan, dan praktik yang dilakukan oleh komunitas masyarakat tertentu sebagai upaya untuk mengaplikasikan hadith Nabi Muhammad saw. Living hadith dapat dilihat dalam berbagai varian, di antaranya tradisi tulis, tradisi lisan, dan tradisi

1 Abdul Mustaqim, dkk., Paradigma Interaksi dan Interkoneksi dalam Memahami Hadith (Yogyakarta: Sukses Offset, 2008), 5.

2 M. Alfatih Suryadilaga, Metodologi Penelitian Living Qur'an dan Hadith (Yogyakarta: TERAS, 2007), 106. 
praktik kehidupan. Di Indonesia, bisa dijumpai berbagai macam tradisi, adat-istiadat, budaya, dan ritual keagamaan. Jika diperhatikan, hampir setiap perayaan hari besar keagamaan di negeri ini dirayakan dengan cara atau tradisi yang berbeda-beda bentuknya. Begitu pula dengan yang terjadi pada masyarakat Jawa. Mereka memiliki prinsip hidup yang kuat dalam pelestarian tradisi leluhurnya.

Sebagian masyarakat Jawa tidak bisa lepas dari ritual selametan. Beberapa Antropolog yang mempelajari kehidupan masyarakat Jawa berpendapat, bahwa selametan adalah jantungnya agama Jawa. ${ }^{3}$ Selametan adalah upacara makan bersama setelah diawali dengan do'a-doa. ${ }^{4}$ Secara umum, tujuan selametan adalah untuk menciptakan keadaan sejahtera, aman, dan terbebas dari gangguan makhluk lain. Sehingga keadaan yang diharapkan adalah selamet, baik bagi yang masih hidup ataupun yang sudah meninggal. ${ }^{5}$ Upacara selametan dapat digolongkan ke dalam empat macam, sesuai dengan peristiwa atau kejadian dalam kehidupan sehari-hari.

Pertama, selametan dalam lingkaran hidup seseorang. Seperti tujuh bulan kehamilan, kelahiran, potong rambut pertama, menyentuh tanah pertama kali, menusuk telinga, sunatan, dan peringatan kematian. Kedua, selametan yang bertalian dengan bersih desa, penggarapan tanah pertanian, dan setelah panen. Ketiga, selametan yang berhubungan dengan hari dan bulan besar Islam. Keempat, selametan pada saat berkenaan dengan kejadian tertentu. Seperti saat perjalanan jauh, menempati rumah baru, tolak balak (ruwatan), dan dan lain sejenisnya. ${ }^{6}$

Kupatan sendiri adalah selametan yang berhubungan dengan hari besar Islam. Tradisi kupatan merupakan salah satu bentuk warisan budaya leluhur yang sampai sekarang masih dilestarikan oleh masyarakat desa

3 Andrew Beatty, Variasi Agama di Jawa (Terj), ed. Ahmad Fedyani Saefuddin (Jakarta: Murai Kencana, 2001), 39.

4 Koentjaraningrat, Beberapa Antropologi Sosial (Jakarta: Dian Rakyat, 2004), 347.

5 Andrew Beatty, Variasi Agama di Jawa (Terj), ed. Ahmad Fedyani Saefuddin, 43.

6 Koentjaraningrat, Beberapa Antropologi Sosial, 347. 
Durenan, kecamatan Durenan, kabupaten Trenggalek, Jawa Timur. Tradisi tersebut merupakan kegiatan sosial yang melibatkan seluruh masyarakat dalam usaha bersama untuk memperoleh keselamatan, dan ketentraman bersama, yang biasa dilakukan pada bulan Syawal. Ketupat adalah makanan khas dari bahan baku beras, dibungkus dengan selongsong dari janur/daun kelapa yang dianyam berbentuk segi empat (diagonal), kemudian direbus. Kupatan ini menjadi salah satu tradisi masyarakat muslim Jawa yang masih dilestarikan sampai sekarang. Umumnya, kupatan hanya dirayakan oleh masyarakat secara individual.

Menurut Clifford Geertz, kupatan adalah tradisi selametan kecil yang dilaksanakan pada hari ketujuh bulan syawal. Hanya mereka yang memiliki anak kecil dan telah meninggal saja, yang dianjurkan untuk mengadakan selametan ini. Hal ini tentu mencakup hampir semua orang yang telah berkeluarga di Jawa, walaupun kenyataannya selametan ini tidak sering diadakan. ${ }^{7}$ Menurut Geertz, tradisi ini umumnya banyak dilaksanakan oleh masyarakat Jawa abangan.

Dalam kepercayaan kejawen, "leluhur" adalah orang-orang yang memiliki sifat luhur pada masa hidupnya, dan setelah meninggal senantiasa dilakukan kontak oleh orang-orang yang masih hidup dengan cara melakukan upacara adat. Lelubur ini biasa disebut dengan istilah nenek moyang. Meski secara fisik keberadaan mereka telah tiada (meninggal), namun mereka dianggap sebagai persona yang telah berhasil membentuk pola kehidupan masyarakat seperti saat ini dan nanti. Lelubur juga dipercayai sebagai arwah yang berada di alam rohani, alam atas, dan alam roh. Seseorang ataupun sesuatu yang dekat dengan yang maha Luhur patut dijadikan sebagai teladan, kaidah atau norma. ${ }^{8}$

Tradisi kupatan dirayakan oleh masyarakat desa Durenan dengan cara membawa ketupat raksasa secara berkeliling, lalu semua orang yang ada saat itu dipersilahkan untuk mengunjungi rumah-rumah warga untuk

7 Clifford Geertz, Agama Jawa, Abangan, Santri, Priyayi dalam Kebudayaan Jawa (Terj), ed. Aswab Mahasin dan Bur Rasuanto (Jakarta, 2013), 105.

8 Muhammad Damami, Makna Agama dalam Masyarakat Jawa (Yogyakarta: LESFI, 2002), 59. 
menikmati hidangan ketupat yang sudah dipersiapkan. Saat pelaksanaan tradisi ini, semua rumah warga masyarakat di desa Durenan terbuka bagi siapapun yang ingin bersilaturahmi dan menikmati hidangan ketupat. Baik orang itu dikenal atau tidak oleh si tuan rumah. Kupatan dengan konsep open house ini menjadi ciri khas masyarakat desa Durenan. pada saat perayaan tradisi ini, selain penduduk setempat juga banyak orang dari luar desa, bahkan luar kota yang datang untuk berkunjung, melihat prosesi acara, dan ikut serta menikmati hidangan ketupat di rumah penduduk setempat. Bagaimanakah resepsi masyarakat atas tradisi ini, kajian living hadith menjadi media untuk dapat menggali maknanya, sekaligus menelusuri teks hadith yang digunakan oleh masyarakat setempat sebagai motivasi pelaksanaan tradisi tersebut. Untuk mendalami dan menyingkap makna dibalik pelaksanaan tradisi kupatan di desa Durenan, pendekatan kualitatif dengan bentuk penelitian lapangan (field research) menjadi pilihan peneliti. ${ }^{9}$

\section{Memaknai Tradisi}

Tradisi adalah kebiasaan yang dilakukan secara turun-temurun oleh suatu masyarakat. Selain itu, tradisi juga berperan sebagai media untuk memperlancar perkembangan pribadi anggota masyarakat. ${ }^{10}$ Tradisi merupakan keyakinan yang dikenal dengan istilah animism dan dinanisme. Animism berarti percaya kepada roh-roh halus atau roh leluhur, yang ritualnya terekspresikan dalam persembahan tertentu di tempat-tempat yang dianggap keramat. ${ }^{11}$

Melalui proses pewarisan, dari orang per-orang atau dari generasi ke generasi, tradisi mengalami perubahan-perubahan, baik dalam skala besar maupun kecilnya. Inilah yang dikatakan dengan invented tradition, dimana tradisi tidak hanya diwariskan secara pasif, tetapi juga direkonstruksi

\footnotetext{
9 Maryaeni, Metode Penelitian Kebudayaan (Jakarta: PT Bumi Angkasa, 2005), 25.

10 Mardimin Johanes, Jangan Tangisi Tradisi (Yogyakarta: Kanisius, 1994), 12.

11 Kuncoroningrat, Sejarah Kebudayaan Indonesia (Yogyakarta: Jambatan, 1954), 103.
} 
dengan maksud membentuk atau menanamkannya kembali kepada orang lain. Oleh karena itu, hubungan Islam dengan tradisi atau kebudayaan selalu terdapat variasi interpretasi sesuai dengan konteks lokalitas masingmasing. ${ }^{12}$ Sedangkan dinamism adalah suatu istilah dalam antropologi untuk menyebut suatu pengertian tentang suatu kepercayaan. Kata ini berasal dari kata Yunani dynamis atau dynaomos yang artinya kekuatan atau tenaga. ${ }^{13}$

Sedangkan secara fenomenologis, realitas yang ada adalah refleksi dari realitas yang tidak berdiri sendiri. Karena ia memiliki makna yang memerlukan penafsiran lebih lanjut. Fenomenologi menerobos fenomena untuk dapat mengetahui makna (hakikat) terdalam dari fenomena tersebut. $^{14}$

Menurut Schutz, pengetahuan mengenai dunia sosial merupakan pengetahuan yang sifatnya inderawi, tidak lengkap, dan tidak pernah utuh, karena keterbatasan kemampuan indera manusia dalam menyerap pengetahuan. Konsep Schutz mengenai dunia sosial ini dilandasi oleh adanya sebuah kesadaran (consciousness), yang didalamnya terdapat hubungan antara orang dengan objek di sekitarnya. ${ }^{15}$ Dengan kesadaran itulah orang akan mampu memberi makna atas berbagai objek yang ada. Menurut Schutz, kategori pengetahuan pertama bersifat pribadi dan unik bagi setiap individu dalam interaksi tatap muka dengan orang lain. Kategori pengetahuan kedua adalah berbagai pengkhasan yang telah terbentuk dan dianut oleh semua anggota budaya.

Dari pandangan Schutz ini, praktek dari sebuah tradisi yang dilakukan secara turun-temurun, termasuk juga yang dilakukan oleh masyarakat di desa Durenan, setidaknya bisa diketahui adanya motif sebab dan motif tujuannya. Motif sebab berkaitan dengan alasan seseorang melakukan

12 Ahmad Khalil, Islam Jawa Sufisme dalam Etika dan Tradisi Jawa (Malang: UINMalang Press, 2008), 1-3.

13 Abu Ahmadi, Perbandingan Agama (Jakarta: Rineka Cipta, 1991), 35.

${ }_{14}$ Margaret M. Poloma, Sosiologi Kontemporer (Jakarta: PT. Raja Grafindo Persada, 2013), 301-302.

15 Basrowi, Pengantar Sosiologi (Bogor: Ghalia Indonesia, 2005), 8. 
sesuatu tindakan, sebagai usahanya menciptakan situasi dan kondisi yang diharapkan di masa mendatang. Motif inilah yang melatarbelakangi seseorang melakukan sebuah tindakan tertentu. Misalnya keinginan menghidupkan tradisi leluhur, pengaruh lingkungan, atau adanya visi yang sama dengan anggota masyarakat.

Sementara motif tujuan merupakan suatu pandangan terhadap faktor-faktor yang menyebabkan seseorang melakukan tindakan tertentu. Dengan kata lain, motif ini adalah gambaran tujuan yang ingin dicapai oleh seseorang dalam melakukan suatu tindakan tertentu. Dalam konteks tradisi kupatan, motif tujuan adalah tujuan yang ingin diraih oleh Masyarakat Durenan, antara lain untuk memperkuat silaturahmi, sebagai sarana, memberikan jamuan pada kerabat, saudara, dan tamu, serta memperkenalkan tradisi kepada generasi penerus dan kepada siapa saja yang hadir.

\section{Resepsi atas Tradisi Kupatan}

Living hadith dimaknai sebagai gejala yang nampak pada masyarakat, berupa pola-pola perilaku yang bersumber dari hadith Nabi Muhammad saw. Pola-pola perilaku di sini merupakan bagian dari respon umat Islam dalam interaksi mereka dengan hadith-hadith Nabi. ${ }^{16}$ Fokus kajian living hadith adalah pada satu bentuk kajian atas fenomena praktik, tradisi, ritual, atau perilaku yang hidup di masyarakat yang memiliki landasan pada hadith Nabi. ${ }^{17}$

Fenomena praktik kehidupan masyarakat yang muncul dari pemahaman keagamaan bukan lagi menjadikan hadith sebagai obyeknya, tetapi pola-pola perilaku masyarakat yang muncul dari hasil pemahaman teks itulah obyeknya. Masyarakat mempraktekan langsung hadith dalam

16 M. Alfatih Suryadilaga, "Model-Model Living Hadith," in Metodologi Penelitian Living Qur'an dan Hadith, ed. Sahiron Syamsuddin (Yogyakarta: TH Press, 2005), 107-114.

17 Saifuddin Zuhri Qudsy, "Living Hadith: Genealogi, Teori, Dan Aplikasi," Living Hadits 1, no. 1 (2016). 
kehidupan sehari-hari, atau setiap apa yang dikerjakan dalam kehidupan berlandaskan hadith Nabi. Fenomena perilaku masyarakat yang disandarkan kepada hadith inilah yang disebut living hadith. ${ }^{18}$

Seperti yang sudah dijelaskan di atas, motif tujuan paling utama diselenggarakannya tradisi kupatan di desa Durenan adalah untuk memperkuat tali silaturahmi antar sesama warga. Namun demikian, masyarakat juga meyakini bahwa kupatan sebagai tradisi luhur, yang harus dijaga dan dilestarikan warisan ajaran Mbah Mesir yang di dalamnya berisi tentang ajaran untuk bersedekah dan memuliakan tamu. Tradisi kupatan bukanlah hal baru bagi masyarakat desa Durenan. Tradisi ini sudah dipraktikkan oleh masyarakat setempat selama hampir 200 tahun. Tradisi ini diyakini sebagai wujud praktik dari keutamaan ajaran hadith Nabi yang berkaitan dengan silaturahmi, sedekah, dan memuliakan tamu yang dituangkan dalam bentuk praktek kupatan buka rumah. Di sinilah hadith hidup di tengah masyarakat. Meskipun pada dasarnya masyarakat kurang mengetahui dan kurang memahami hadith mana yang dijadikan sebagai dasar praktik kupatan, tetapi mereka meyakini bahwa tradisi itu adalah bentuk praktik nilai luhur dari silaturahmi. Bagi mereka yang awam, meyakini bahwa apabila tidak melaksanakan tradisi ini, tidak akan mendapatkan barokah para Kyai, sehingga mereka tidak merasa nyaman dan tenang dalam kehidupan sehari-harinya. Soal hadith apa yang dijadikan dasar oleh masyarakat dalam mempraktikkan tradisi kupatan, apabila ditarik dari hadith Rasulullah, bentuknya bisa dilihat sebagaimana diagram di bawah ini:

18 M. Alfatih Suryadilaga, Aplikasi Penelitian Hadith Dari Teks Ke Konteks (Yogyakarta: TERAS, 2009), 174. 


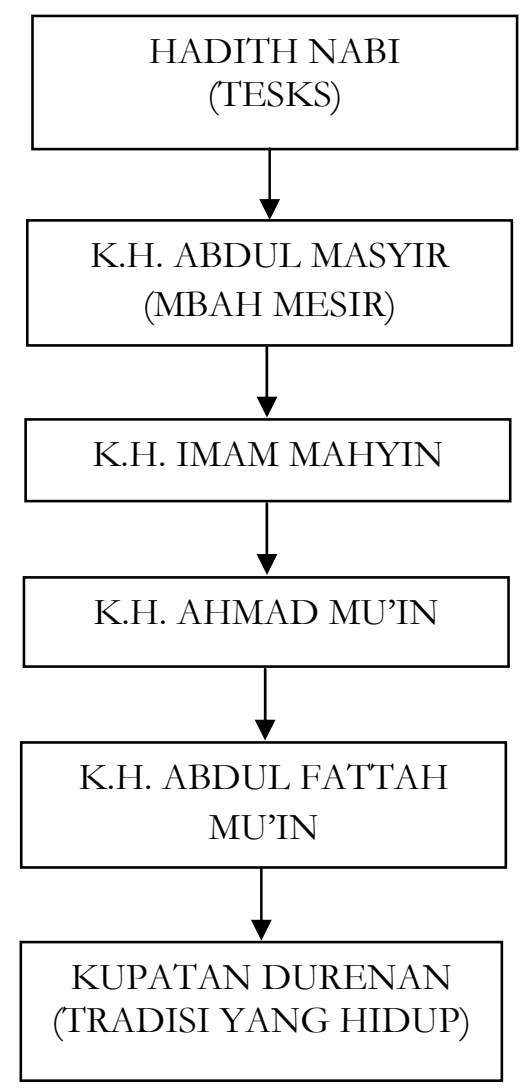

Diagram (1): Sumber dasar hadith dari praktik tradisi Kupatan

Diagram di atas menunjukkan bahwa Mbah Mesir adalah orang pertama yang mengawali tradisi kupatan di desa Durenan. Pada mulanya, saat Mbah Mesir masih hidup, tradisi ini belum tersebar luas, dan belum banyak masyarakat yang mengikutinya. Setelah Mbah Mesir wafat, tradisi ini tetap dihidupkan oleh tokoh-tokoh penerusnya, antara lain K.H. Imam Mahyin, K.H. Ahmad Mu'in, dan yang hingga saat ini diteruskan oleh K.H Abdul Fattah Mu'in. Kini, tradisi kupatan terus dipraktikkan oleh masyarakat Durenan secara alami, tanpa adanya intruksi dari sang Kyai. Di sinilah hadith hidup di tengah keseharian masyarakat, bahkan sudah melebur dengan adat setempat. 
Dalam kajian living hadith, tokoh-tokoh yang berperan penting dalam tradisi tersebut berperan sebagai penghubung antara hadith dan masyarakat. Tanpa adanya tokoh-tokoh tersebut, ajaran dari hadith-hadith Nabi Muhammad saw., tidak akan sampai kepada masyarakat. Bahkan, bisa dikatakan masyarakat akan menjawab tidak tahu, apabila ditanya tentang hadith apa yang mendasari dilaksanakannya tradisi kupatan. Akan tetapi bila ditanya tentang tujuan diselenggarakannya tradisi tersebut, mereka lebih bisa memaknai nilai-nilai luhur di dalamnya.

Di sini terlihat, bahwa masyarakat lebih mengutamakan praktik dari sebuah tradisi yang diwariskan secara turun-temurun daripada mencari tahu dalil (hadith) mana yang mendasari pelaksanaan dan berkembangnya tradisi tersebut. Kultur masyarakat Durenan yang taat kepada Kyai turut mempengaruhi keyakinan mereka, bahwa ajaran-ajaran yang telah disampaikan oleh para Kyai terdahulu memiliki barokah tersendiri bagi yang mau menjalankannya secara istiqomah. Dalam konteks ini, Kyai diyakini sebagai pribadi yang lebih mengerti tentang agama dan hal-hal yang terkait urusan agama. Oleh sebab itulah, Kyai diyakini oleh masyarakat umum sebagai sosok yang patut untuk dijadikan sebagai rujukan atau model pribadi yang baik. ${ }^{19}$

Jika dilihat lebih mendalam, dari motif tujuan masyarakat Durenan mempraktikkan tradisi kupatan, bisa disimpulkan bahwa hadith-hadith yang mendasari tradisi kupatan, antara lain:

\section{Puasa Syawal}

Hadith Imam Muslim dalam Shahih Muslim nomor 1991 menyatakan bahwa: "Barang siapa yang berpuasa Ramadhan, kemudian diikuti dengan puasa enam hari pada bulan Syawwal, maka ia seolah-olab puasa setabun." Hadith inilah yang pada dasarnya mendasari masyarakat Durenan untuk

19 Nur Kafid, "From Personal to Social Transformation: A Phenomenological Study on the Life of "Kyai Kampung," JURNAL KOMUNITAS: Research \& Learning in Sociology and Anthropology 6, no. 2 (2014): 336-344. 
secara bersama-sama menjalankan puasa syawal. Puasa enam hari di bulan syawal ini merupakan bagian dari puasa sunnah yang telah dicontohkan oleh Rasulullah. Kegiatan ini sudah menjadi bagian dari adat masyarakat Durenan sebelum menyambut datangnya hari kupatan. Masyarakat Durenan menjalani aktifitas puasa syawal ini dengan penuh kesadaran dan keyakinan bahwa itu bagian dari mengikuti ajaran leluhur sebagaimana telah dicontohkan oleh Mbah Mesir. Meskipun sebagian dari mereka, terutama masyarakat awamnya, tidak mengetahui adanya dalil dari hadith yang menganjurkan untuk berpuasa syawal.

Meski puasa syawal dapat dilakukan pada awal, pertengahan, atau akhir bulan syawal, bahkan boleh pula dilaksanakan secara berurutan hari maupun terpisah-pisah, tetapi masyarakat desa Durenan lebih memilih hari ke dua syawal hingga datangnya hari raya kupatan. Hal ini lebih didasarkan karena adanya keyakinan menyesuaikan seperti yang telah dicontohkan oleh Mbah Mesir.

\section{Silaturahmi}

Hadith Imam Bukhari dalam Shahih Bukhari nomor 5986 menyatakan bahwa: "Barangsiapa ingin dibentangkan pintu rizki untuknya dan dipanjangkan ajalnya hendaknya ia menyambung tali silaturrabmi."

Hadith ini juga menjadi dasar dari tradisi kupatan yang telah dipraktikkan oleh masyarakat Durenan. Silaturahmi menjadi hal yang sangat diutamakan oleh masyarakat melalui praktik kupatan. Melalui tradisi inilah silaturahmi antara warga, santri, dan Kyai terjalin lebih kuat. Sebagaimana ditekankan dalam hadith di atas, dengan tujuan mendapatkan banyak manfaat, sebagaimana diakui oleh Madzuhal bahwa "Acara ini adalah adat yang baik, adat yang islami, warga semangat menjalankan agar mendapat barokah." ${ }^{20}$. Dengan kata lain, melalui tradisi kupatan inilah diyakini akan tercipta ukhuwah islamiyah yang semakin kuat.

20 Wawancara dengan Madzuhal, pada tanggal 2 Juli 2017. 
Selain itu, warga juga meyakini bahwa tradisi kupatan akan mendatangkan berkah bagi kehidupan mereka. Melalui tradisi inilah mereka memberikan sedekah harta berupa makanan kepada siapa saja yang bertamu. Sebagaimana diakui oleh Anik, "Kita masyarakat Durenan ikblas memberikan hidangan kupat kepada para tamu. Kalau kita memberi ke orang lain insyaalloh rejeki kita bisa makin banyak.". ${ }^{21}$

Pemahaman warga tentang konsep sedekah ini kemungkinan berasal dari peran dakwah para Kyai di desa Durenan. Melalui tradisi kupatan ini masyarakat mengerti nilai-nilai luhur yang terkandung dalamnya. Selain itu, warga juga meyakini bahwa melalui sedekah yang dipraktikkan dalam bentuk tradisi kupatan, akan menjadikan mereka berumur panjang. sebagaimana disampaikan oleh Warsidi, bahwa "Orang yang saling bersilaturahmi itu akan dipanjangkan umurnya oleh Gusti Allah".22 Bahkan ajaran Islam sendiri memberikan catatan akan pentingnya menjaga tali silaturahmi, dan memberikan penegasan (ancaman) bagi siapa saja yang memutuskan tali silaturahmi kepada sesamanya. ${ }^{23}$

\section{Sedekah}

Hadith Imam Bukhari dalam Shahih Bukhari nomor 1356, menyatakan bahwa "Tidak ada hari dimana hamba-hamba Allah berada di waktu pagi melainkan ada dua malaikat yang turun, dimana salah satu di antara keduanya berdo'a: "Wahai Allah, berikanlah ganti kepada orang yang suka berinfaq". Dan malaikat lain berdo'a:"Wahai Allah binasakanlah orang yang kikir".

Hadith juga bisa dirujuk sebagai dasar bagi masyarakat desa Durenan dalam mempraktikkan tradisi open house saat acara kupatan. Sehingga, meski tamu yang berkunjung ke rumahnya sangat banyak, tidak lantas membuat mereka terbebani. Justru, semakin banyak tamu yang berkunjung ke rumah mereka untuk menikmati hidangan kupat, diyakini akan semakin banyak pula berkah yang mereka dapatkan.

\footnotetext{
21 Wawancara dengan Anik, pada tanggal 2 Juli 2017.

22 Wawancara dengan Warsidi, pada tanggal 2 Juli 2017.

23 Yunahar Ilyas, Kuliah Akblak (Jakarta: LPPI, 2007), 189-190.
} 
Shodaqoh atau sedekah adalah pemberian yang dilakukan secara sukarela, ikhlas, atau tanpa pamrih, semata-mata untuk mengharap ridha Allah yang memiliki nilai sosial, menolong, atau membantu kesulitan yang tengah dialami oleh orang lain. ${ }^{24}$ Dalam tradisi Kupatan di desa Durenan, hadith tentang sedekah terwujud dalam bentuk praktik open house. Masyarakat mempraktikkan hadith tersebut dalam bentuk hidangan ketupat yang mereka berikan kepada siapapun yang berkunjung ke rumahnya. Meski banyak dari warga desa Durenan tidak mengetahui bahwa yang mereka praktikkan sejalan denga hadith Rasulullah, tetapi mereka meyakini bahwa yang mereka lakukan telah sesuai dengan ajaran dari para leluhurnya.

\section{Memuliakan Tamu}

Hadith Imam Bukhari dalam Shahih Bukhari nomor 5585, menyatakan "Siapa yang beriman kepada Allah dan hari akbir hendaklah dia berkata baik atau diam, siapa yang beriman kepada Allah dan hari akbir hendaklah dia menghormati tetangganya, dan barangsiapa yang beriman kepada Allah dan hari akbir maka hendaklah dia memuliakan tamunya".

Hadith tersebut juga dapat dijadikan sebagai rujukan dari fakta lapangan terkait tradisi kupatan. Realitas bahwa masyarakat desa Durenan sangat antusias dalam menyambut dan memuliakan para tamu yang datang ke rumahnya saat pelaksanaan tradisi kupatan, didasari adanya keyakinan itu terkait dengan pemahaman mereka tentang konsep sedekah, sebagaimana di atas.

Memuliakan tamu, mereka wujudkan dalam bentuk sambutan hangat, serta senantiasa menampakkan kerelaan dan rasa senang atas pelayanan yang diberikan. Sikap ramah terhadap tamu jauh lebih berkesan di hati mereka. Melayani tamu dengan berbagai macam hidangan ketupat itulah yang mereka maknai sebagai sikap memuliakan tamu. Bahkan

${ }^{24}$ Muhammad Muhyidin, Keajaiban Shodaqoh (Yogyakarta: DIVA Press, 2008), 258. 
mereka mempersilahkan siapapun yang lewat di depan rumahnya untuk menikmati hidangan yang sudah disiapkan, sampai ada pula sebagian dari mereka yang tidak segan untuk 'merayu' para tamunya supaya mau menambah makanan yang sudah dihabiskan. Biasanya mereka mengatakan dengan istilah "monggo, ditanduk kupatipun" (silahkan ditambah ketupatnya). Masyarakat desa Durenan menganggap, siapapun yang melintasi rumah, bahkan jalan raya Durenan sebagai tamu mereka, tanpa memandang asal, bahkan agamanya. Masyarakat non-muslim pun turut berkunjung ke rumah-rumah warga. ${ }^{25}$ Di sinilah terlihat wujud nyata dari praktik memuliakan tamu. Tanpa mengenal istilah tamu khusus, warga mana, dan agamanya apa. Dengan kata lain, tradisi ini mendorong orang untuk lebih mengedepankan prinsip kearifan lokal, tidak hanya menunjukkan wajah dan orientasi agama, tetapi juga berwajah dan berorientasi sosial. Sebagaimana terjadi dalam praktik tradisi lokal masyarakat di Jawa yang sudah mengalami akulturasi dengan budaya Islam. ${ }^{26}$ Sekat agama dan status sosial melebur menjadi satu, ke dalam prinsip menghormati dan memuliakan tamu.

Dalam batasan hadith di atas, tuan rumah wajib memberikan pelayanan berupa makanan sesuai dengan kemampuan, tanpa ada unsur paksaan. Masyarakat pun tidak pernah merasa terbebani dengan adanya tradisi ini. Bahkan atas keinginan sendiri, mereka menabung jauh-jauh hari sebelum diselenggarakannya acara tersebut, dengan tujuan agar saat tiba hari raya kupatan mereka bisa memberikan jamuan terbaik kepada para tamunya. Sebaliknya, orang yang bertamu pun harus senantiasa memperlihatkan akhlak yang baik, agar orang yang menerimanya pun senang untuk melayani. Meskipun tamu tersebut tidak dikenal sebelumnya oleh sang pemilik rumah sekalipun. Hal terpenting bagi warga desa Durenan adalah memberikan sambutan yang hangat kepada siapapun

25 Observasi pada tanggal 2 Juli 2017.

${ }^{26}$ M Aly Haedar, "PERGESERAN PEMAKNAAN RITUAL 'MERTI DUSUN'; STUDI ATAS RITUAL WARGA DUSUN CELENGAN, TUNTANG, SEMARANG," Al-A'raf: Jurnal Pemikiran Islam dan Filsafat XIII, no. 1 (2016): 1-23. 
yang berkunjung.

Ketentuan-ketentuan tersebut telah dipraktikkan oleh oleh masyarakat desa Durenan melalui tradisi kupatan. Dari sini terjalin keharmonisan diantara warga, baik yang muslim maupun non-muslim. Keharmonisan inilah yang pada tahap selanjutnya, menjadi modal sosial mereka dalam mewujudkan tatanan kehidupan yang aman dan damai.

\section{Penutup}

Tradisi kupatan di desa Durenan merupakan sebuah perayaan selametan yang dipraktikkan oleh masyarakat Jawa dengan cara open house pada hari kedelapan bulan syawal. Menyiapkan hidangan ketupat untuk para tamu, melayani para tamu dengan baik adalah tujuan mereka untuk mendapatkan berkah kupatan. Meski tidak semua warga mengetahui tentang dalil hadith atas pelaksanaan tradisi tersebut, tetapi mereka meyakini bahwa yang mereka lakukan adalah warisan yang baik dari para leluhurnya. Pasalnya, menjaga ajaran leluhur diyakini akan mendatangkan berkah bagi kehidupan mereka kelak. Keyakinan inilah yang sampai hari ini menjadi dasar bagi warga desa Durenan untuk terus melestariakn tradisi kupatan hingga saat ini.

\section{Referensi}

Abdul Mustaqim, dkk. Paradigma Interaksi Dan Interkoneksi Dalam Memahami Hadith. Yogyakarta: Sukses Offset, 2008.

Ahmadi, Abu. Perbandingan Agama. Jakarta: Rineka Cipta, 1991.

Basrowi. Pengantar Sosiologi. Bogor: Ghalia Indonesia, 2005.

Beatty, Andrew. Variasi Agama Di Jawa (Terj). Edited by Ahmad Fedyani Saefuddin. Jakarta: Murai Kencana, 2001.

Damami, Muhammad. Makna Agama Dalam Masyarakat Jawa. Yogyakarta: LESFI, 2002. 
Geertz, Clifford. Agama Jawa, Abangan, Santri, Priyayi Dalam Kebudayaan Jawa (Terj). Edited by Aswab Mahasin dan Bur Rasuanto. Jakarta, 2013.

Haedar, M Aly. "PERGESERAN PEMAKNAAN RITUAL 'MERTI DUSUN'; STUDI ATAS RITUAL WARGA DUSUN CELENGAN, TUNTANG, SEMARANG.” Al-A'raf: Jurnal Pemikiran Islam dan Filsafat XIII, no. 1 (2016): 1-23.

Ilyas, Yunahar. Kuliah Akblak. Jakarta: LPPI, 2007.

Johanes, Mardimin. Jangan Tangisi Tradisi. Yogyakarta: Kanisius, 1994.

Kafid, Nur. "From Personal to Social Transformation: A Phenomenological Study on the Life of 'Kyai Kampung."' JURNAL KOMUNITAS:

Research \& Learning in Sociology and Anthropology 6, no. 2 (2014): 336-344.

Khalil, Ahmad. Islam Jawa Sufisme Dalam Etika Dan Tradisi Jawa. Malang: UIN-Malang Press, 2008.

Koentjaraningrat. Beberapa Antropologi Sosial. Jakarta: Dian Rakyat, 2004.

Kuncoroningrat. Sejarah Kebudayaan Indonesia. Yogyakarta: Jambatan, 1954.

M. Alfatih Suryadilaga. Aplikasi Penelitian Hadith Dari Teks Ke Konteks. Yogyakarta: TERAS, 2009.

Maryaeni. Metode Penelitian Kebudayaan. Jakarta: PT Bumi Angkasa, 2005.

Muhyidin, Muhammad. Keajaiban Shodaqoh. Yogyakarta: DIVA Press, 2008.

Poloma, Margaret M. Sosiologi Kontemporer. Jakarta: PT. Raja Grafindo Persada, 2013.

Qudsy, Saifuddin Zuhri. "Living Hadith: Genealogi, Teori, Dan Aplikasi.” Living Hadits 1, no. 1 (2016).

Suryadilaga, M. Alfatih. Metodologi Penelitian Living Qur'an Dan Hadith. Yogyakarta: TERAS, 2007.

—_ "Model-Model Living Hadis." In Metodologi Penelitian Living Qur'an Dan Hadith, edited by Sahiron Syamsuddin, 107-114. Yogyakarta: TH Press, 2005. 